\title{
HX575: established biosimilarity in the treatment of renal anemia and 10 years of clinical experience
}

This article was published in the following Dove Press journal:

Drug Design, Development and Therapy

\section{Frank Dellanna' \\ David Goldsmith ${ }^{2}$ \\ Andriy Krendyukov ${ }^{3}$ \\ Andreas Seidl ${ }^{4}$ \\ Nadja Höbel ${ }^{5}$ \\ Christian Combe 6,7}

'MVZ Davita Rhein-Ruhr, Düsseldorf, Germany; 'Division of Nephrology, Guy's and St Thomas' Hospitals, London, UK; ${ }^{3} \mathrm{Hematology/Nephrology,}$ Hexal AG, Holzkirchen, ${ }^{4}$ Technical Development Biosimilars, Hexal AG, Oberhaching, ${ }^{5}$ Biostatistics Medical Affairs/Late Phase, Hexal AG, Holzkirchen, Germany; ${ }^{6}$ Service de Néphrologie Transplantation Dialyse Aphérèse, Centre Hospitalier Universitaire de Bordeaux,

${ }^{7}$ Université Bordeaux, INSERM I026, Bordeaux, France
Correspondence: Andriy Krendyukov Sandoz Biopharmaceuticals, Hexal AG, Industriestr. 25, D-83607 Holzkirchen, Germany

Tel +498024 4764855

Fax +498024 4762979

Email andriy.krendyukov@sandoz.com

\begin{abstract}
Erythropoiesis-stimulating agents, such as recombinant human erythropoietin, are commonly used for the treatment of anemia in patients with chronic kidney disease (CKD). In 2007, HX575 (Binocrit $^{\circledR}$ ) became the first biosimilar epoetin alfa to be approved by the European Medicines Agency (EMA). The decision to approve a biosimilar is based on the totality of evidence obtained in a comprehensive comparability exercise that involves extensive analytical characterization, nonclinical studies and clinical studies. The development process for HX575 included extensive analytical characterization and comparison with the reference epoetin alfa. This was followed by a clinical development program, comprising Phase I pharmacokinetic/ pharmacodynamic studies to show bioequivalence to the reference medicine and a confirmatory Phase III study to demonstrate therapeutic effectiveness in anemia related to CKD. In addition to the comparability exercises, extensive clinical experience over the last decade also confirms that HX575 provides an effective treatment for CKD-related anemia, with a favorable safety profile. Growing clinical experience with EMA-approved biosimilars, including HX575, should offer additional reassurance to health care professionals and patients that these agents are as effective and well tolerated as others in the therapeutic class.
\end{abstract}

Keywords: Binocrit, HX575, anemia, chronic kidney disease, biosimilars

\section{Introduction}

Erythropoiesis-stimulating agents (ESAs), such as recombinant human erythropoietin, are commonly used for the treatment of anemia in patients with chronic kidney disease (CKD). In 2007, HX575 (Binocrit ${ }^{\circledR}$; Sandoz GmbH, Kundl, Austria) became the first biosimilar epoetin alfa to be approved by the European Medicines Agency (EMA). Recently, the Food and Drug Administration Oncologic Drugs Advisory Committee voted favorably following the review of the file for the proposed biosimilar epoetin alfa in the United States. ${ }^{1}$ The decision to approve a biosimilar is based on the totality of evidence obtained in a comprehensive comparability exercise that involves extensive analytical characterization, nonclinical studies and clinical (Phase I pharmacokinetic $[\mathrm{PK}]$ /pharmacodynamics [PD] and confirmatory Phase III) studies. ${ }^{2-4}$ The present study reviews the journey of HX575 from development to approval and to the accumulation of a decade of clinical experience in patients with CKD, which provides an excellent example of the successful demonstration of biosimilarity.

\section{Analytical and preclinical characterization of $\mathrm{HX575}$}

Analytic and characterization studies are an important part of the evidence dossier on which approval of a biosimilar is based. ${ }^{5}$ These studies are performed using an array of standard and advanced techniques to assess each molecular attribute. HX575 and the reference epoetin alfa have an identical amino acid sequence and therefore the same 

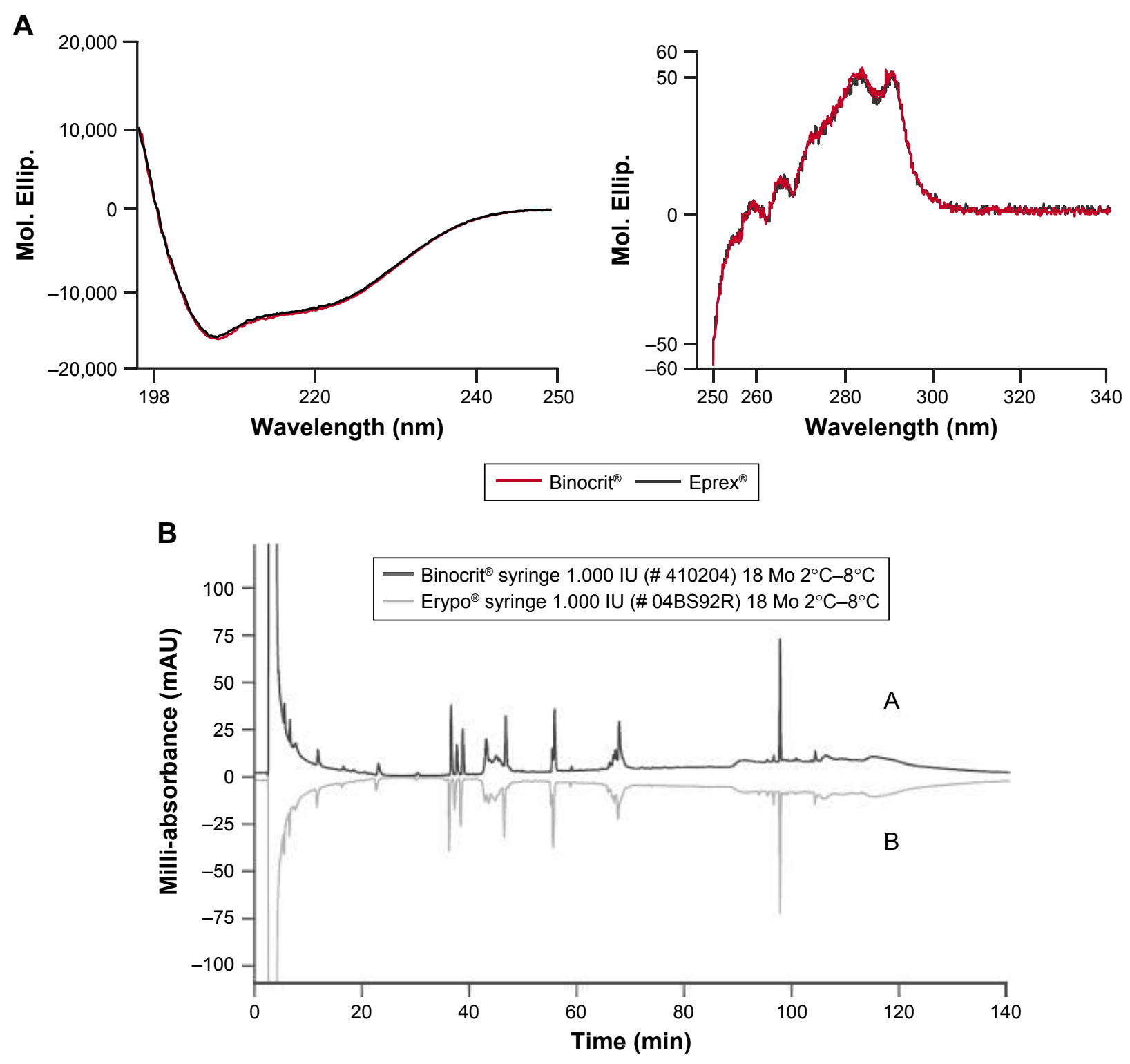

Figure I Comparison of (A) far- and near-UV circular dichroism spectra and (B) peptide mapping profiles for $\mathrm{HX} 575$ and reference epoetin alfa. ${ }^{5}$ Reproduced with permission from European Association of Hospital Pharmacists. Brockmeyer C, Seidl A. Binocrit: assessment of quality, safety and efficacy of biopharmaceuticals. EJHP Pract. $2009 ; 15: 34-40 .^{5}$

Abbreviations: Mol. Ellip., molar ellipticity; IU, international units; mAU, milli-absorption units; UV, ultraviolet.

primary structure, as demonstrated by peptide mass fingerprint analysis (Figure 1B), liquid chromatography-tandem mass spectrometry (MS) and Edman sequencing. Using circular dichroism analyses, the two products were also shown to have comparable higher-order (secondary and tertiary) protein structures (Figure 1A). In addition, a similar isoform pattern was shown for HX575 and the reference epoetin alfa, using isoelectric focusing gel electrophoresis and capillary zone electrophoresis. Posttranslational modifications were also shown to be similar using a variety of techniques (eg, gas chromatography-mass spectrometry of monosaccharides and glycan mapping by high performance anion exchange chromatography with pulsed amperometric detection and matrix-assisted laser desorption ionization-time of flight mass spectrometry on $\mathrm{N}$ - and $\mathrm{O}$-glycans), along with receptor binding (by surface plasmon resonance spectroscopy) and biological activity (by cell-based and in vivo assays). ${ }^{5}$

\section{Clinical development program and initial EMA approval of $\mathbf{H X 5 7 5}$}

Three open-label, randomized, parallel-group Phase I studies were included in the clinical development program for HX575. ${ }^{6-8}$ These studies compared the pharmacological properties of HX575 with those of existing epoetins following intravenous (IV) or subcutaneous (SC) administration in healthy volunteers. HX575 and comparator epoetins were 
found to be bioequivalent with respect to their pharmacological profiles. ${ }^{6-8}$ For example, in the study comparing IV HX575 and the reference epoetin alfa, the hemoglobin $(\mathrm{Hb})$ profiles of both treatments were similar, with an area under the effect curve ratio for $\mathrm{Hb}\left(\mathrm{AUEC}_{\mathrm{Hb}}\right)$ of $99.9 \%$ (90\% confidence interval [CI] 98.5\%-101.2\%), the primary PD endpoint. ${ }^{6}$ PK parameters showed minor differences after single dosing, but not at steady state doses. The primary PK parameter was the epoetin area under the curve calculated over $0-36$ hours $\left(\mathrm{AUC}_{\tau}\right)$. After multiple doses, $\mathrm{HX} 575$ was bioequivalent to the reference medicine with $\mathrm{AUC}_{\tau}$ ratio of $89.2 \%$ (90\% CI 82.5\%-96.2\%). ${ }^{6}$ Across all Phase I studies, multiple doses of study medication were well tolerated, with similar safety profiles across the treatment groups. No anti-epoetin antibodies were detected..$^{6-8}$

A confirmatory Phase III study evaluated IV HX575 versus the marketed epoetin reference medicine (Eprex ${ }^{\circledR} /$ Erypo $^{\circledR}$; Janssen-Cilag, High Wycombe, UK) in 479 adult patients with $\mathrm{CKD}$ on dialysis. ${ }^{9}$ Dialysis patients with $\mathrm{Hb}$ levels of 10.0-13.0 g/dL received either IV HX575 or reference medicine, one to three times per week for 28 weeks. Therapeutic equivalence of the two treatments was demonstrated (Figure 2); mean changes in Hb levels were 0.15 (0.09) g/dL with HX575 and $0.06(0.12) \mathrm{g} / \mathrm{dL}$ with reference medicine, with a difference between groups of $0.08 \mathrm{~g} / \mathrm{dL}$ (95\% CI -0.17 to 0.34 ). The safety profile of HX575 over 56 weeks was similar to that of the reference medicine, with no differences in the incidence of drug-related or serious adverse events (AEs). No patients developed neutralizing anti-erythropoietin antibodies. The selection of the study population for this

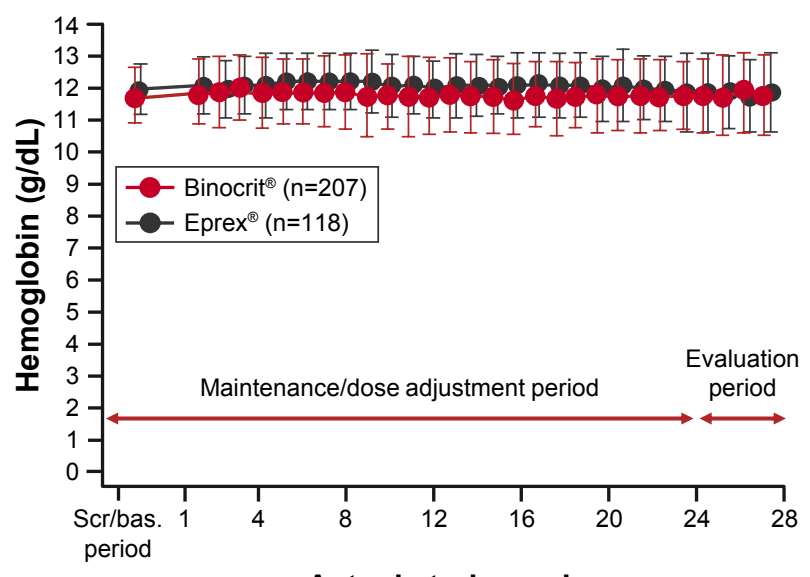

Actual study week

Figure 2 Mean hemoglobin levels over time in the confirmatory Phase III study of intravenous $\mathrm{HX575}$ and the reference epoetin alfa. ${ }^{9}$ Reproduced with permission from Dustri-Verlag. Haag-Weber M, Vetter A, Thyroff-Friesinger U; INJ-Study Group. Therapeutic equivalence, long-term efficacy and safety of HX575 in the treatment of anemia in chronic renal failure patients receiving hemodialysis. Clin Nephrol. 2009;72:380-390. ${ }^{9}$

Abbreviation: Scr/bas., screening/baseline visit. study was based on EMA guidance for the clinical development of biosimilar medicines comprising recombinant erythropoietins. ${ }^{10}$ This guidance recommends renal anemia as the most sensitive indication in which to show similar clinical efficacy between the biosimilar and reference medicines. It also recommends that pre-dialysis and dialysis patients should not be mixed in the same study population.

The clinical development program provided sufficient confirmatory evidence for biosimilarity to be established; IV HX575 was approved by the EMA for all indications in which the epoetin reference medicine $\left(\operatorname{Eprex}^{\circledR} /\right.$ Erypo $^{\circledR}$ ) was approved at that time: anemia associated with renal failure, chemotherapy-induced anemia, and moderate anemia prior to major elective orthopedic surgery where there is a high risk for perioperative transfusions., ${ }^{9,11,12}$

\section{Further clinical development and recent EMA approval of SC HX575}

SC administration of the epoetin reference medicine $\left(\right.$ Eprex $^{\circledR} /$ Erypo $\left.^{\circledR}\right)$ in patients with CKD was contraindicated in the European Union (EU) between 2002 and 2006 after increased reports of pure red cell aplasia (PRCA) with this medicine. ${ }^{13}$ Therefore, a comparative study of SC HX575 and the reference epoetin alfa in CKD-related anemia could not be performed initially. SC use of the reference medicine was subsequently re-instated, allowing such a study to be conducted; however, two patients developed neutralizing anti-erythropoietin antibodies following SC administration of HX575 in this trial. ${ }^{14}$ Results of a thorough root-cause analysis indicated that atypical increased tungsten levels in pre-filled syringes precipitated immunogenic reactions with two batches of the study medication; ${ }^{15,16}$ the manufacturing process of the syringe barrels was subsequently changed to consistently reduce the tungsten levels to specified low levels (introduction of low-tungsten syringes).

An open-label, multi-center, single-arm, Phase III study, SENSE, was subsequently conducted in Europe to evaluate the safety and immunogenicity of SC HX575 in 416 pre-dialysis and dialysis patients. ${ }^{17}$ A total of 250 patients (60.1\%) were naïve to ESA treatment and 166 (39.9\%) were already receiving ESA maintenance therapy. Mean (standard deviation [SD]) treatment duration of SC HX575 therapy was 43.4 (15.8) weeks and 45.3 (13.7) weeks in the ESA-naïve and maintenance groups, respectively. Binding anti-erythropoietin antibodies were detected at very low levels by radioimmunoprecipitation (RIP) assay in seven patients (1.7\%; incidence 0.019), while no patient developed neutralizing antibodies as determined in a cell-based epoetin neutralizing assay. 
There were no clinical signs of immunogenicity or hypersensitivity. Of the seven patients with a positive binding RIP assay, four were tested to be negative at later time points while continuing SC HX575 treatment. ${ }^{17}$ SC HX575 was effective at maintaining $\mathrm{Hb}$ levels, regardless of whether patients had previously received ESA therapy. On the basis of these findings, HX575 was approved by the EMA for SC administration in the nephrology indication in March $2016 .{ }^{18}$

In addition, the randomized, double-blind, parallelgroup, multi-center, 52-week Phase III ACCESS (A Clinical Research Study in Chronic Kidney Disease \& Anemia) study was conducted in the United States to evaluate the maintenance of SC HX575 versus the US-licensed reference medicine (Epogen ${ }^{\circledR}$; Amgen Inc, Thousand Oaks, CA, USA and Procrit ${ }^{\circledR}$; Janssen, Pennsylvania, USA) in 435 patients on dialysis. ${ }^{19}$ For the primary endpoint, mean (SD) change in $\mathrm{Hb}$ level from baseline to evaluation period was -0.11 (1.001) g/dL with SC HX575 and 0.01 (0.953) g/dL with $\mathrm{SC}$ reference medicine. The estimated difference in $\mathrm{Hb}$ was $0.0926 \mathrm{~g} / \mathrm{dL}$ with $90 \%$ CIs (0.2264-0.0413) entirely within the pre-specified equivalence limits $(-0.5 \mathrm{~g} / \mathrm{dL}$, $0.5 \mathrm{~g} / \mathrm{dL}$ ). Nine patients were tested positive (transiently) for anti-epoetin antibodies by RIP assay (seven patients in the HX575 group and two in the reference group), including two patients (one patient from each treatment arm) who were already RIP-positive at baseline (before which all patients had been receiving pre-study treatment with the reference medicine). No patient was tested positive for neutralizing antibodies. HX575 is not available in the United States, for either IV or SC administration; however, accumulating clinical trial data adds to the body of evidence in favor of its well-tolerated effectiveness in CKD patients with anemia.

\section{Post-approval safety study}

As part of the post-EMA-approval commitment for HX575, the large-scale $(n=1,695), 6$-month, open, single-arm safety study, EPO-PASS, was conducted in 10 European countries in patients with renal anemia. ${ }^{20}$ Patients were converted from any pre-study ESA to IV HX575 treatment. The study period covered 770 patient-years and no unexpected safety findings were reported over the treatment period. The overall AE profile was in line with the expectations for this CKD population and consistent with the results of previous studies with ESAs in general, ${ }^{21}$ as well as HX575 and the epoetin reference medicine $\left(\right.$ Eprex $^{\circledR} /$ Erypo $\left.^{\circledR}\right) .{ }^{9}$ Thrombotic vascular events are of interest with the use of ESAs and were reported in $11.9 \%$ of patients $(0.2612$ per patient-year $)$ in EPO-PASS $;{ }^{20}$ this incidence is similar to that reported in other studies of HX575, ${ }^{22}$ as well as studies of other ESAs. ${ }^{23}$ Also in EPO-PASS, tumor incidence was 1.4\% (0.0299 per patient-year), and no subject developed anti-epoetin antibodies. ${ }^{20}$ Mean $\mathrm{Hb}$ levels were effectively maintained between the narrow range of 11.2 and $11.3 \mathrm{~g} / \mathrm{dL}$, following a switch from a broad range of pre-study ESAs, with stable overall mean HX575 doses. The proportion of patients within the $\mathrm{Hb}$ target range increased from $57.5 \%$ at baseline to $66.8 \%$ at study end. ${ }^{20}$

\section{Additional clinical experience from multi- and single-center studies}

Since approval, a wealth of real-world data on the effectiveness and safety of biosimilar epoetins has been accrued in various multi- and single-center studies. ${ }^{22,24-27}$ MONITORCKD5 (Multi-level Evaluation of Anaemia Treatment, Outcomes, and Determinants in Chronic Kidney Disease Stage 5) was a large, prospective, observational, 24-month pharmacoepidemiological study of the effectiveness and safety of HX575 in 2,023 stage 5 CKD patients with renal anemia started on HX575 de novo or by conversion from another ESA in 10 European countries..$^{22}$ On average, both $\mathrm{Hb}$ and HX575 dose remained stable over the 24 months. The safety profile of HX575 was in line with the reference medicine. In total, $26.4 \%$ of patients experienced thromboembolic events prior to enrollment and $14.4 \%$ of patients experienced thromboembolic events during the 24-month observation period; this on-treatment incidence rate for thromboembolic events is again consistent with previous studies of HX575 and other ESAs. ${ }^{20,21,23}$ No cases of antiepoetin antibodies or PRCA were reported, and serious drug-related AEs were rare $(0.5 \%) .^{22}$

In a large retrospective German study, ESA utilization was found to be similar for patients on chronic hemodialysis receiving reference or biosimilar medicines. ${ }^{24}$ Patients $(\mathrm{n}=6,177)$ with CKD stage 5 treated with ESAs for at least six 3 -month periods (accounting quarters) were identified from a population-based database of accounting information of Bavarian physicians and pharmacy claims data (January 2008 to December 2010). Defined daily dose (DDD) was used to determine the mean ESA consumption; for short-acting ESAs, the DDD is 1,000 international units. Patients receiving reference short-acting ESAs had a median DDD consumption of 0.77 , while patients receiving a biosimilar short-acting ESA had a median DDD consumption of 0.82 ; doses were not increased when the therapy was switched from the reference medicine to the biosimilar ESA. 
A multi-center observational study, also conducted in Germany, assessed $\mathrm{Hb}$ levels and ESA dose in hemodialysis patients $(n=326)$ treated with IV HX575. ${ }^{25}$ Most of the patients ( $\mathrm{n}=298$ ) were switched from other ESAs to HX575 at the start of the 6-month observation period. Treatment with HX575 effectively maintained stable $\mathrm{Hb}$, and no dose penalty was observed in patients switched to HX575 from other ESAs. HX575 treatment was also well tolerated, with no unexpected serious AEs reported. ${ }^{25}$

\section{Summary}

The successful approval and clinical use of $>20$ biosimilars over the last decade affirms the integrity of the biosimilar pathway of the EMA. In addition to the comparability exercises, extensive clinical experience over the last decade also confirms that HX575 provides an effective treatment for anemia related to $\mathrm{CKD}$, with a safety profile similar to that of other ESAs. HX575 has generated more than 400,000 patient-years of experience worldwide (in CKD and chemotherapy-induced anemia) until April 2016, ${ }^{18}$ and with more widespread adoption, patient exposure continues to increase. Growing clinical experience with EMA-approved biosimilars, including HX575 IV and SC, should offer additional reassurance to health care professionals and patients that these agents are as effective and well tolerated as others in the therapeutic class.

\section{Acknowledgments}

Editorial support was provided by Tony Reardon, Spirit Medical Communications Ltd., supported by Hexal AG.

\section{Author contributions}

All authors contributed equally to the preparation of the manuscript, including:

- Substantial contributions to the conception or design of the work; or the acquisition, analysis, or interpretation of data for the work

- Drafting the work or revising it critically for important intellectual content

- Final approval of the version to be published

- Agreement to be accountable for all aspects of the work in ensuring that questions related to the accuracy or integrity of any part of the work are appropriately investigated and resolved.

\section{Disclosure}

FD, DG, and CC have served as advisors to Sandoz (study Steering Committee members). AK and AS are employees of Sandoz International GmbH/Hexal AG. NH was an employee of Sandoz International $\mathrm{GmbH} / \mathrm{Hexal} \mathrm{AG}$ at the time of writing. The authors report no other conflicts of interest in this work.

\section{References}

1. Food and Drug Administration Briefing Document. BLA125545 "Epoetin Hospira", a proposed biosimilar to Epogen/Procrit (epoetin alfa). 2017. Available from: https://www.fda.gov/downloads/Advisory Committees/CommitteesMeetingMaterials/Drugs/OncologicDrugs AdvisoryCommittee/UCM559967.pdf. Accessed June 14, 2017.

2. European Medicines Agency. Guideline on Similar Biological Medicinal Products. London: EMA; 2014. Available from: http:/www.ema. europa.eu/docs/en_GB/document_library/Scientific_guideline/2014/10/ WC500176768.pdf. Accessed June 7, 2017.

3. European Medicines Agency. Guidelines on Similar Biological Medicinal Products Containing Biotechnology-Derived Proteins as Active Substance: Non-Clinical and Clinical Issues. London: EMA; 2014. Available from: http://www.ema.europa.eu/docs/en_GB/ document_library/Scientific_guideline/2015/01/WC500180219.pdf. Accessed June 7, 2017.

4. US Food \& Drug Administration. Biosimilarity guidelines. 2015. Available from: http://www.fda.gov/Drugs/GuidanceComplianceRegulatoryInformation/Guidances/ucm290967.htm. Accessed January 26, 2017.

5. Brockmeyer C, Seidl A. Binocrit: assessment of quality, safety and efficacy of biopharmaceuticals. EJHP Pract. 2009;15:34-40.

6. Sörgel F, Thyroff-Friesinger U, Vetter A, Vens-Cappell B, Kinzig M. Bioequivalence of HX575 (recombinant human epoetin alfa) and a comparator epoetin alfa after multiple intravenous administrations: an open-label randomised controlled trial. BMC Clin Pharmacol. 2009;9:10.

7. Sörgel F, Thyroff-Friesinger U, Vetter A, Vens-Cappell B, Kinzig M Bioequivalence of HX575 (recombinant human epoetin alfa) and a comparator epoetin alfa after multiple subcutaneous administrations. Pharmacology. 2009;83:122-130.

8. Sörgel F, Thyroff-Friesinger U, Vetter A, Vens-Cappell B, Kinzig M. Biosimilarity of HX575 (human recombinant epoetin alfa) and epoetin beta after multiple subcutaneous administration. Int J Clin Pharmacol Ther. 2009;47:391-401.

9. Haag-Weber M, Vetter A, Thyroff-Friesinger U; INJ-Study Group. Therapeutic equivalence, long-term efficacy and safety of HX575 in the treatment of anemia in chronic renal failure patients receiving hemodialysis. Clin Nephrol. 2009;72:380-390.

10. European Medicines Agency. Guideline on Non-Clinical and Clinical Development of Similar Biological Medicinal Products Containing Recombinant Erythropoietins (Revision). London: EMA; 2010. Available from: www.ema.europa.eu/docs/en_GB/document_ library/Scientific_guideline/2010/04/WC500089474.pdf. Accessed June 7, 2017.

11. European Medicines Agency. Binocrit, scientific discussion. 2006. Available from: http://www.ema.europa.eu/docs/en_GB/document_ library/EPAR_-_Scientific_Discussion/human/000725/WC500053615. pdf. Accessed June 7, 2017.

12. Eprex summary of product characteristics. Available from: https://www. medicines.org.uk/emc/medicine/20282. Accessed June 7, 2017.

13. Macdougall IC, Casadevall N, Locatelli F, et al. Incidence of erythropoietin antibody-mediated pure red cell aplasia: the prospective immunogenicity surveillance registry (PRIMS). Nephrol Dial Transplant. 2015;30:451-460.

14. Haag-Weber M, Eckardt KU, Hörl WH, Roger SD, Vetter A, Roth K. Safety, immunogenicity and efficacy of subcutaneous biosimilar epoetin- $\alpha$ (HX575) in non-dialysis patients with renal anemia: a multicenter, randomized, double-blind study. Clin Nephrol. 2012;77:8-17. 
15. Seidl A, Hainzl O, Richter M, et al. Tungsten-induced denaturation and aggregation of epoetin alfa during primary packaging as a cause of immunogenicity. Pharm Res. 2012;29:1454-1467.

16. Rubic-Schneider T, Kuwana M, Christen B, et al. T-cell assays confirm immunogenicity of tungsten-induced erythropoietin aggregates associated with pure red cell aplasia. Blood Adv. 2017;1:367-379.

17. Casadevall N, Dobronravov V, Eckardt K-U, et al. Evaluation of the safety and immunogenicity of subcutaneous HX575 epoetin alfa in the treatment of anaemia associated with chronic kidney disease in pre-dialysis and dialysis patients. Clin Nephrol. In press 2017.

18. Novartis. Sandoz receives EC approval for subcutaneous route of administration in biosimilar Binocrit's ${ }^{\circledR}$ nephrology indication (press release). 2016. Available from: https://www.novartis.com/news/media-releases/ sandoz-receives-ec-approval-subcutaneous-route-administrationbiosimilar. Accessed June 7, 2017.

19. Weir M, Pergola PE, Agrawal RL, et al. A comparison of the safety and efficacy of HX575 (epoetin alfa proposed biosimilar) with epoetin alfa in patients with end-stage renal disease. Am J Nephrol. 2017; 46:364-370.

20. Hörl WH, Locatelli F, Haag-Weber M, Ode M, Roth K; Epo-PASS study group. Prospective multicenter study of HX575 (biosimilar epoetin- $\alpha$ ) in patients with chronic kidney disease applying a target hemoglobin of 10-12 g/dl. Clin Nephrol. 2012;78:24-32.

21. Abraham I, MacDonald K. Clinical safety of biosimilar recombinant human erythropoietins. Expert Opin Drug Saf. 2012;11:819-840.
22. London G, Mann J, Goldsmith D, et al. Long-term treatment with biosimilar epoetin- $\alpha$ (HX575) in hemodialysis patients with renal anemia: real-world effectiveness and safety in the MONITOR-CKD5 study. Clin Nephrol. In press 2017.

23. Singh AK, Szczech L, Tang KL, Barnhart H, Sapp S, Wolfson M, et al. Correction of anemia with epoetin alfa in chronic kidney disease. N Engl J Med. 2006;355:2085-2098.

24. Hörbrand F, Bramlage P, Fischaleck J, Hasford J, Brunkhorst R. A population-based study comparing biosimilar versus originator erythropoiesis-stimulating agent consumption in 6,117 patients with renal anaemia. Eur J Clin Pharmacol. 2013;69:929-936.

25. Turner M, Hartmann U, Dellanna F. HX575 epoetin-alfa effectively maintains stable haemoglobin levels in patients on haemodialysis with symptomatic anaemia due to chronic renal failure. BANTAO J. 2009;7(Suppl 1):32.

26. Zoccolo AM, Battiato S, Mauceri B, Milana F, Napoletano F, Barbera R. Switching from epoetin alfa and darbepoetin to biosimilar epoetin alfa in patients with CRI in the uraemic phase. Poster presented at: The Italian Society of Nephrology Annual Meeting; October 6-9; 2010; Rimini.

27. Sacco P, Patrone P, Ervo R, et al. Treatment of anaemia with HX575 (recombinant human epoetin alfa) in haemodialysis patients: Liguria's multi-centre experience. Poster presented at: The Italian Society of Nephrology Annual Meeting; November 21-24; 2011; Genoa.
Drug Design, Development and Therapy

\section{Publish your work in this journal}

Drug Design, Development and Therapy is an international, peerreviewed open-access journal that spans the spectrum of drug design and development through to clinical applications. Clinical outcomes, patient safety, and programs for the development and effective, safe, and sustained use of medicines are the features of the journal, which

\section{Dovepress}

has also been accepted for indexing on PubMed Central. The manuscript management system is completely online and includes a very quick and fair peer-review system, which is all easy to use. Visit http://www.dovepress.com/testimonials.php to read real quotes from published authors.

Submit your manuscript here: http://www.dovepress.com/drug-design-development-and-therapy-journal 